\title{
Technological Control of the Heredity of Operational Quality Parameters for Machine Parts
}

\author{
M.L. Kheifetz ${ }^{1 *}$, A.S. Vasilyev ${ }^{2}$, S.A. Klimenko ${ }^{3}$ \\ ${ }^{1}$ Department of Physical and Technical Sciences of the National Academy of Sciences of Belarus, \\ 66, Nezavisimosti Av., Minsk, 220072, Belarus; \\ ${ }^{2}$ Bauman Moscow State Technical University, p. 1, d. 5, st. Baumanskaya $2^{\text {nd }}$, Moscow, 105005, Russia; \\ ${ }^{3}$ V. Bakul Institute for Superhard Materials of the National Academy of Sciences of Ukraine, \\ 2, st. Avtozavodskaya, 2, Kiev, 04074, Ukraine \\ * Corresponding author. Tel.:+375 (17) 28407 75. E-mail:mlk-z@mail.ru
}

\begin{abstract}
Technological heredity of operational properties in the processes of manufacturing, operation and restoration of machine parts is proposed to describe by the graph reflecting the coefficients of transmission and mutual influence of physical, mechanical and geometric parameters. The technological control methods of the heredity of operational properties of parts are considered, including: measuring parameters of the most critical parts; determining technological heredity mechanisms on the basis of transfer coefficients and mutual influence of operational properties; analyzing technological barriers during intensive effects of energy flows, developing measures for controlling technological processes.
\end{abstract}

\section{Keywords}

Technological heredity; operational properties; processed material; part surfaces; physico-mechanical and geometric quality parameters.

(c) M.L. Kheifetz, A.S. Vasilyev, S.A. Klimenko, 2019

\section{Introduction}

The heredity in engineering technology is understood as the phenomenon of transferring the properties of the processed object from previous operations and transitions to the next ones, which further affects the operational properties of machine parts $[1,2]$. The carriers of heredity information are the processed material and the part surfaces with all the variety of parameters describing them. Information carriers are actively involved in the technological process and in operation, going through various modes and transitions, experiencing the effects of technological factors [3, 4].

In the technological chain and at the stage of operation, there are some kind of "barriers". Some technological factors cannot overcome them, and in this case do not affect the final properties of the object. Other factors pass through such "barriers", but their influence on the final properties significantly decreases $[1,3]$. The most significant "barrier" is thermal operations, as well as operations accompanied by surface deformation and hardening, as they change the microstructure of the processed material, the microgeometry of the formed surface, lead to the deformation of the part and distortion of its shape. During these operations, various surface defects, such as structural heterogeneity, pores, and microcracks, can develop or heal. Consequently, it is possible to control the process of technological and operational heredity so that properties that positively affect the quality of the part are maintained throughout the entire technological process, while properties that affect negatively are eliminated at the beginning of the process $[4,5]$.

A distinctive feature of existing approaches to the definition and prediction of quality indicators for engineering products is the use of the superposition principle, according to which each of the existing technological factors is independent of the others, and the result of joint action is determined by their partial sum represented in one form or another $[3,4]$.

However, the technological systems are multiply connected, production objects are characterized by nonlinearity, irreversibility and disequilibrium, and the application of the superposition principle reduces the 
multiply connected interactions carried out in the technological systems to simply connected interactions, ignoring the mutual influence of technological factors $[4,5]$.

With the growth of requirements for the quality of machining parts surfaces, methods for determining and predicting quality based on the principle of superposition become of little use, since the effect of the mutual influence of factors is comparable with the results of their direct impact. The process of ensuring the product properties should be considered as a set of interacting processes, changing and preserving properties $[2,6]$.

\section{Design decision making methodology}

The multiplicity of product properties, each of which is characterized by a corresponding set of quality indicators, is also a manifestation of the multiply connected technological factors in the formation of product quality. The product properties are interconnectedly formed during its manufacture, however, in the production practice of mechanical engineering this fact is not sufficiently taken into account. Isolated consideration of the formation process of selected quality indicators can lead to serious errors in the design and implementation of technological processes $[1,2]$.

Technical difficulties associated with the description of multiply connected interactions in the formation of various quality indicators in the processing and hardening of product surfaces, as well as in the process of its operation can be overcome by applying the design decision making methodology $[2,6]$.

Reducing the dimension in describing the transfer of product properties in technological and operational processes is done by highlighting the order parameters and determining the system state modes. After that, in each of the modes, it is advisable to consider the relationship of the main indicators of the product quality with the determining order parameter and the conditions for their sustainable formation $[7,8]$.

\section{Quality indicators of machine parts surfaces}

The quality indicators of engineering products, which are the main ones, are divided into two categories $[9,10]$ : the first category includes those that are characterized by heredity phenomena related to the properties of product materials; the second category comprises the quality indicators related to the geometrical parameters of their surfaces.
Indicators of both categories in multiply connected technological and operational environments mutually influence each other. Geometrical product parameters, such as product configurations and sizes, can influence the stresses distributed in the base material and surface layers. On the contrary, the stresses generated during the technological hardening process and operation stages may, over time, lead to changes in the geometrical parameters of the parts. This testifies to the interconnection and conditionality of the phenomena accompanying the technological and operational processes.

The most complete heredity of the main quality indicators is revealed when considering the sequence of processes from the synergistic positions of the joint action of technological factors with the mutual influence of indicators $[11,12]$.

The initial quality indicators for machine parts at various scale levels (Fig. 1) vary during operation $[6,11]$. The exceptions are the residual stresses and the structure of the base material, which can be maintained until the rubbing surfaces of the parts are completely destroyed. In most cases, already during the period of running-in, the roughness and structure of the surface relief significantly change. The waviness and structure of the surface layers of the part change with steady wear, and the geometric shape of the friction surface remains within the allowable values adopted during manufacture almost to the end of the friction unit service, if its performance is assessed by accuracy parameters $[2,5,6]$.

Reducing the sensitivity of technological and operational environments to the changes in the conditions for the implementation of production modes and the use of products allows to carry out the directional formation of quality indicators in the life cycle of engineering products for the least cost $[2,10]$. The functional models of multiply connected technological environments allow, depending on the formulation of the problem being solved, to reduce its dimension by highlighting a number of essential connections and suppressing insignificant connections while maintaining correctness and adequacy $[6,12]$.

\section{The model of multi-connected interactions of the environment}

The mathematical apparatus of the methodology is based on the main provisions $[2,12]$ :

- the quality of the part is formed throughout its technological history and a variety of quality indicators is the result of the history;

- any technological and related impact on the workpiece changes all quality indicators; 


\begin{tabular}{|c|c|c|c|}
\hline \multirow{2}{*}{ Manufacturing quality indicator } & \multicolumn{3}{|c|}{ Wear process period } \\
\cline { 2 - 4 } & running-in & normal wear & accelerated wear \\
\hline $\begin{array}{c}\text { Dimensional accuracy and shape } \\
\text { (flatness, non-circularity, etc.) }\end{array}$ & & & \\
\hline Waviness & & & \\
\hline Roughness & & & \\
\hline Residual stress & & & \\
\hline Main material structure & & & \\
\hline Surface layer structure & & & \\
\hline Surface relief structure & & & \\
\hline
\end{tabular}

Fig. 1. Diagram of changes in initial quality indicators of product surface during operation (shaded areas characterize the duration of preservation of the initial values in the geometric parameters, residual stresses and the material structure within permissible deviations)

- any quality indicator, while changing, leads to the change in all other quality indicators of the workpiece.

The characteristics of technological environments and the laws of their changing allowed to form the main task of the directional formation of product quality indicators: knowing the initial and final properties of the production object to determine the most optimal technological environment from the point of properties transformation.

As a result, a general methodic approach was proposed to ensure the directional formation of optimal product properties (Fig. 2).

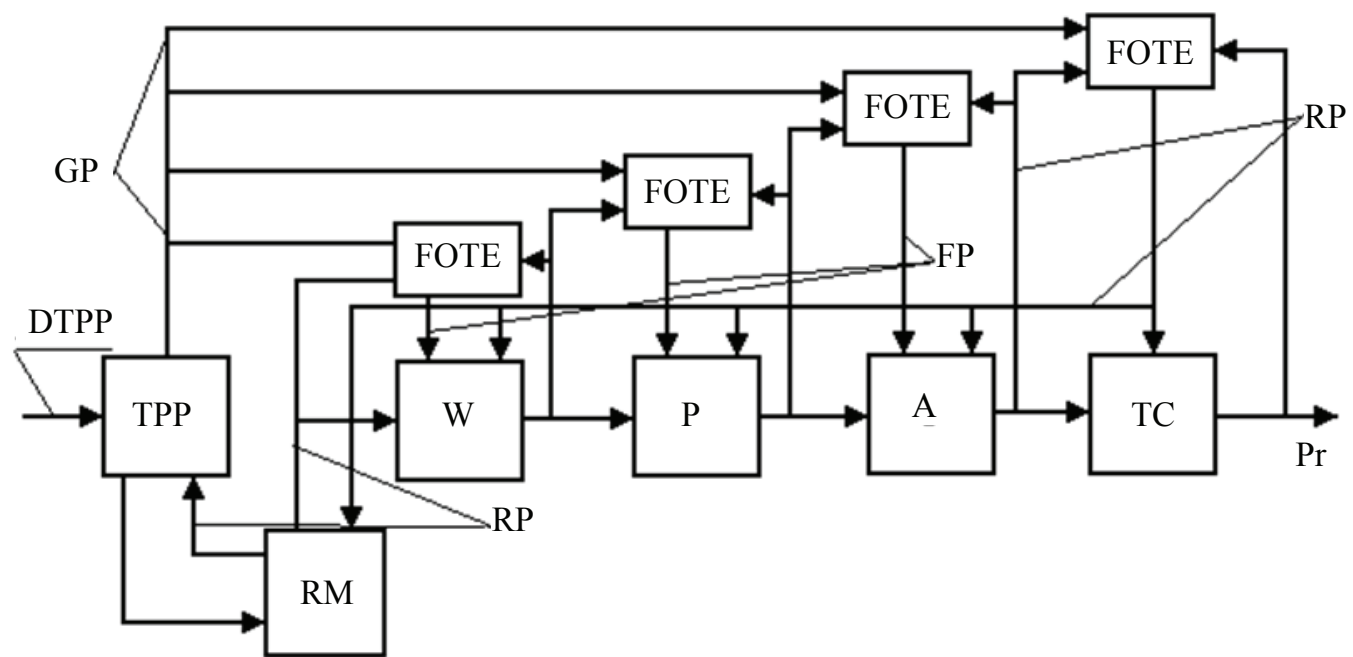

Fig. 2. Conceptual diagram of directional formation of optimal product properties:

Pr - product; GP, RP, FP - given, real, formed product properties, respectively; TPP - technological preparation of production; $\mathrm{RM}$ - raw materials manufacture; $\mathrm{W}$ - workpiece production; $\mathrm{P}$ - parts manufacture; A - assembly; TC - testing and control;

DTPP - design and technological product parameters; FOTE - formation of optimal technological environments 
The most important feature of the approach is the formation of the end-to-end product manufacturing process of the optimal technological environment for each technological redistribution, which ensures the most rational distribution of the quality indicators by redistribution and gives the necessary quality to the process of product quality formation. By changing the environment or its characteristics, it is possible to control the formed properties of the products

On the basis of comparing the characteristics of the basic technological process environments and the desired processes, the necessary corrective actions can be determined on changes in the composition, structure and conditions of interaction of both the elements of the technological environment and the latter with the production object.

According to the conceptual approach, it was proposed to determine the following coefficients [2]:

- the coefficient of the operational change of the $i$-th quality indicator using the $j$-th technological method $-\left(m_{i}\right)_{j}$;

- the coefficient of the changes in the $i$-th product quality indicator related to the conditions of the $j$-th technological method realization $-\left(u_{i}\right)_{j}$;

- the coefficient of the changes in the $i$-th quality indicator in the interaction with the environment of the operation level that implements the $j$-th technological method $-\left(S_{i}\right)_{j}$.

Operationally forming component $\left(K_{i}\right)_{j}^{\text {on }}$ of the indicator $K_{i}$ value:

$$
\left(K_{i}\right)_{j}^{\text {on }}=\left(m_{i}\right)_{j}\left(K_{i}\right)_{j-1}+\left(u_{i}\right)_{j}\left(K_{i}\right)_{j-1},
$$

where $\left(K_{i}\right)_{j}$ is a set of values of the quality product indicators after its manufacture taking into account the laws of technological heredity; $\left(K_{i}\right)_{j-1}$ is a set of values of the quality indicators characterizing the state of the product after the previous operation.

If the method is not implemented,

$$
\left(m_{i}\right)_{j}=1,\left(u_{i}\right)_{j}=0 \text {, otherwise } 0<\left(m_{i}\right)_{j} \leq 1 \text {. }
$$

The change in the sign and value of the quality indicator occurs as a result of the cumulative change in the coefficients $\left(m_{i}\right)_{j}$ and $\left(u_{i}\right)_{j}$. For each technological method, standard implementation conditions were found to determine the values of $\left(m_{i}\right)_{j}$. The coefficient $\left(m_{i}\right)_{j}$ takes into account the standard conditions of the method implementation (in particular, the standard economically justified processing conditions), while $\left(u_{i}\right)_{j}$ includes the conditions different from the standard ones, as well as other conditions that additionally characterize the environment (basing and fixing the workpiece, the elastic characteristics of the technological system elements etc.).

The analytical determination of the coefficients $\left(m_{i}\right)_{j},\left(u_{i}\right)_{j},\left(S_{i}\right)_{j}$ is impossible, so they are obtained by statistical processing of the experimental material.

For a specific method with an implementation index $r$, the term $\left(u_{i}\right)_{j}\left(K_{i}\right)_{j-1}$ is allocated to the systematic component $C$ :

$$
\left[\left(K_{i}\right)_{j}^{\text {on }}\right]_{r}=\left(m_{i}\right)_{j}\left[\left(K_{i}\right)_{j-1}^{\text {on }}\right]_{r}+C .
$$

\section{Methods for determining the transfer coefficients}

When determining the coefficients of operational changes in quality indicators $\left(m_{i}\right)_{j}$, some methods are used to maximize the intersection of input and output values of quality indicators, as well as average the range boundaries (Fig. 3).

Knowing $\left(m_{i}\right)_{j}$, values $\left(u_{i}\right)_{j}$ are determined in accordance with

$$
\left[\left(u_{i}\right)_{j}\right]_{\gamma}=\left[\left(K_{i}\right)_{j}^{\text {on }}\right]_{\gamma} /\left[\left(K_{i}\right)_{j-1}^{\text {on }}\right]_{\gamma}-\left(m_{i}\right)_{j} .
$$

Knowing $\left(m_{i}\right)_{j},\left(u_{i}\right)_{j}$

$$
\left(S_{i}\right)_{j}=\frac{\left(K_{i}\right)_{j}^{\text {on }}}{\left(K_{i}\right)_{j-1}^{\text {on }}}
$$

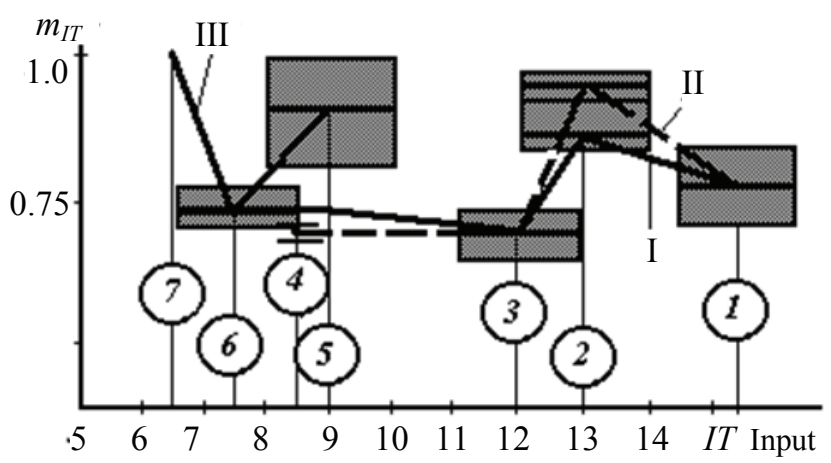

Fig. 3. Comparison of the coefficients of operational changes in size accuracy $\left(m_{I T}\right)$ for processing methods of external cylindrical surfaces:

$1-4$ - draft, semi-finishing, finishing, and fine turning, respectively; $5-7$ - preliminary, final, fine grinding, respectively; I, III - the method of maximum intersection of sets; II - the method of border averaging 
the tables of averaged coefficients of operational changes of properties $\left(m_{i}\right)_{j}$ are used for the main technological methods of processing external and internal cylindrical surfaces, as well as planes.

It is established that the optimal error in determining the coefficients of operational changes in the quality indicators of the processed workpieces for abrasive processing methods is on average 3 times higher than for blade processing, which indicates the greater sensitivity of the respective process environments to the changes in the implementation conditions and the state of the objects forming them.

The average value of the relative error in determining the $m_{I T}$ coefficient of rapid change in dimensional accuracy for a group of methods for turning and grinding parts with wear-resistant coatings was $2.5 \%$, and the roughness coefficient $m_{R a}$ was $11.0 \%$. The dependences of the characteristics of the technological environments of the operation level on the state of the objects forming them are adequately represented by linear regression models or piecewise linearly approximated with a relative error not exceeding $10 \%$ (Fig. 4 and Fig. 5).

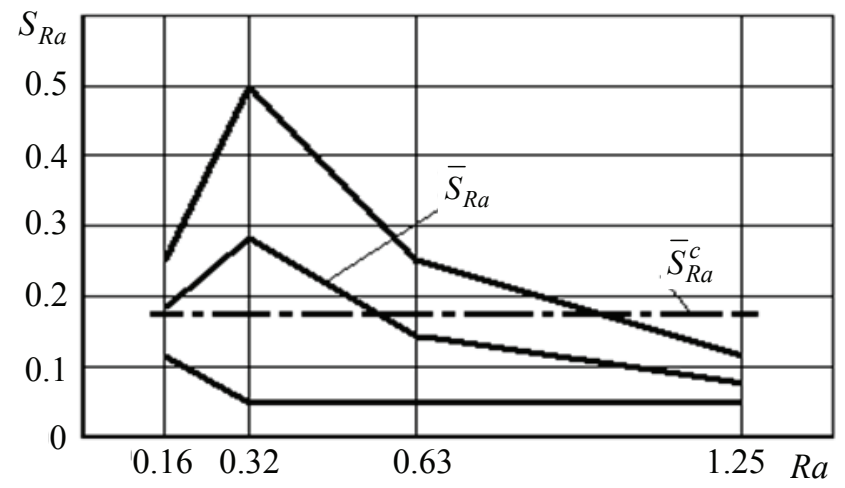

Fig. 4. The dependence of the $S_{R a}$ coefficient on the initial roughness of the parts with superfinish:

$\bar{S}_{R a}$ - arithmetic average value; $\bar{S}_{R a}^{c}$-average constant value

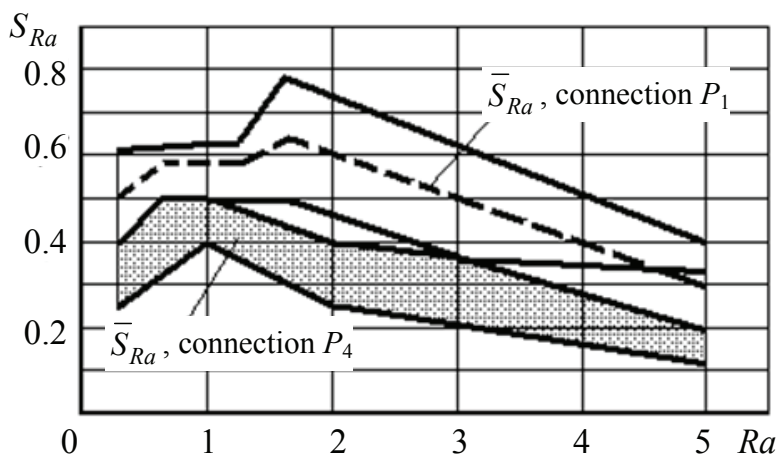

Fig. 5. The dependence of the $S_{R a}$ coefficient on the initial roughness of the parts when grinding with an abrasive belt ( $\bar{S}_{R a}$ - arithmetic average coefficient value)
It has been established that the preservation and mutual influence of the properties is especially manifested while flat-topped diamond-abrasive machining, polishing and superfinish are used, when the removed allowance is within the initial height of roughness irregularities.

\section{Determination of the conservation and mutual influence coefficients}

The multiply connected technological environments, difference in physical processes accompanying the interaction of environments with the object of labor are the main reasons for the lack of a unified methodological approach to determining the elements of the conservation factors and the mutual influence of the generated properties $k_{i j}$ for the matrix $\left[k_{i j}\right]$. The coefficients are determined during the implementation of the end-to-end process of the product manufacturing with a continuous study of the production item quality.

The primary value $k_{i j}$ for the initial phase of the process:

$$
k_{i j} \approx \frac{\left(K_{i}\right)_{1}-S_{i j}\left(K_{i}\right)_{0}}{\left(K_{i}\right)_{0}},
$$

where $\left(K_{i}\right)_{1}$ is the value of the indicator $K_{i}$ after completing the operation; $\left(K_{i}\right)_{0}$ is the value of the indicator $K_{i}$ before starting the operation; $S_{i j}$ is the coefficient of the change in the quality indicator during the interaction of the item of production with the technological environment of the operation level. In contrast to $m_{i}, u_{i}$, the coefficients $k_{i j}$ have a physical dimension.

The proposed apparatus for describing the transformation of quality indicators, taking into account their interaction and mutual influence in multiply connected technological environments, is adequate to the actual processes of forming the properties of engineering products and can be used to predict technological solutions $[2,10]$.

\section{Determination of processing error}

Consideration of the mutual influence of technological factors in the interaction of technological environment with the production object allows to make appropriate clarifications in the analytical method of determining the total error of processing. The errors that occur during processing of the workpiece are interconnected, affect each other and the total error of processing. The components of the error are formed as a result of the interaction of the workpiece with the technological environment of the operation level, and with the technological environment of the process level. 
For components of the processing error is fair

$$
\left[\begin{array}{c}
\Delta Y \\
\varepsilon \\
\Delta H \\
\Delta u \\
\Delta T
\end{array}\right]=\left[\begin{array}{ccccc}
1 & a_{\Delta Y, \varepsilon} & a_{\Delta Y, \Delta H} & a_{\Delta Y, \Delta u} & a_{\Delta Y, \Delta T} \\
a_{\varepsilon, \Delta Y} & 1 & a_{\varepsilon, \Delta H} & a_{\varepsilon, \Delta u} & a_{\varepsilon, \Delta T} \\
a_{\Delta H, \Delta Y} & a_{\Delta H, \varepsilon} & 1 & a_{\Delta H, \Delta u} & a_{\Delta H, \Delta T} \\
a_{\Delta u, \Delta Y} & a_{\Delta u, \varepsilon} & a_{\Delta u, \Delta H} & 1 & a_{\Delta u, \Delta T} \\
a_{\Delta T, \Delta Y} & a_{\Delta T, \varepsilon} & a_{\Delta T, \Delta H} & a_{\Delta T, \Delta u} & 1
\end{array}\right]_{j}\left[\begin{array}{c}
\Delta Y \\
\varepsilon \\
\Delta H \\
\Delta u \\
\Delta T
\end{array}\right]_{d j}
$$

where $(\Delta Y, \varepsilon, \Delta H, \Delta u, \Delta T)_{j}^{T}$ is a column vector of component error values (error caused by elastic deformations; installation error; tuning error; error caused by dimensional wear; error caused by thermal deformations) determined by the mutual influence; $a$ is error transformation ratios taking into account the mutual influence of errors; $(\Delta Y, \varepsilon, \Delta H, \Delta u, \Delta T)^{T}{ }_{d j}$ is a column vector of deterministic values, the components of the errors determined on the basis of the traditional calculation and analytical method; $T$ is a transpose symbol.

The square of the final value of the total error $\Delta$ is determined in the following form

$$
\Delta^{2}=\left[\lambda_{i} P_{i}\right]^{T}\left[P_{i}\right],
$$

where $\lambda_{i}$ - coefficients determining the shape of the distribution curve of the error component $P_{i}$.

Taking into account the multiply connected technological environments in determining the total error of processing allows to improve the accuracy of existing calculation methods $[2,6]$.

\section{The formation model of quality indicators}

The developed apparatus for describing the transformation of the product properties helps to distribute the levels of the product properties according to the stages of the manufacture technological process in the desired way. For any part of the end-to-end of product manufacturing process and for any of its properties, the desired level of values of the corresponding quality indicators can be determined and optimized, if necessary, based on the developed methodology.

So, for example, at the end of the preparation redistribution, the achieved values of quasi-stable $K_{c}^{\text {procur }}$ and changing $K_{v}^{\text {procur }}$ quality indicators are defined as follows:

$$
\left\{\begin{array}{l}
K_{c}^{\text {procur }}=S_{c}^{\text {procur }} K^{\mathrm{m}}+k_{c}^{\text {procur, } \mathrm{m}} K^{\mathrm{m}} ; \\
K_{v}^{\text {procur }}=S_{v}^{\text {procur }} K^{\mathrm{m}}+k_{v}^{\text {procur, } \mathrm{m}} K^{\mathrm{m}},
\end{array}\right.
$$

where $S_{c}^{\text {procur }} S_{v}^{\text {procur }}$ - the coefficients of changes in the production object properties as a result of its interaction with the technological environment of the procurement processing level; $K^{\mathrm{m}}$ - values of quality indicators of the source material; $k_{c}^{\text {procur, } \mathrm{m}}, k_{v}^{\text {procur, } \mathrm{m}}-$ the coefficients of preservation and mutual influence of the source material properties, which are manifested in the procurement phase of the end-to-end of the product manufacturing process.

Similar ratios can be defined for processing and hardening of parts. They can be considered as a formation model of the product properties in the endto-end manufacture technological process. Practically any stage of operations from $N$ group has the following form

$$
K_{N}=H_{N} K^{\mathrm{m}},
$$

where $K_{N}$ is the value of the quality indicator formed after stage $N ; H_{N}$ is the transformation ratio of the product properties in relation to the source properties $K^{\mathrm{m}}$.

By introducing a set of optimization criteria, one can proceed to solving the problems of optimizing the values of quality indicators for each stage (operation) of the technological process. Since not all quality indicators are equivalent from the standpoint of technological support of their values, it is advisable to determine the desired levels not for each indicator, but only for difficult-to-ensure quality indicators, considering "by default" that other indicators will be provided. The use of a production item "passport", including, for example, data on the most difficult to achieve values of quality indicators and the total number of its surfaces, makes it possible to correctly reduce the dimension of technological problems to be solved.

\section{The determination of operation transfer characteristics}

The functional models of multi-connected technological environments allow, depending on the formulation of the problem, to reduce its dimension by 
highlighting a number of essential connections and suppressing insignificant connections while maintaining correctness and adequacy.

Reducing the sensitivity of technological and operational environments to the changes in the conditions for the implementation of production modes and the use of products makes it possible to carry out targeted quality indicators in the life cycle of engineering products with the lowest cost.

\section{The structure of the relationship of inherited properties}

The technological process of manufacturing and operating parts can be represented as a graph, highlighting the procurement, draft operations, finishing operations, as well as performance stages [6].
The graph, as a rule, is oriented, and the quality parameters are interconnected (Fig. 6).

The initial vertex of the graph, when describing the technological process, is a workpiece $\mathrm{W}$, the final vertex is the finished part $\mathrm{P}$ in operation. Oriented edges of the graph show the transfer of operational properties of the part during processing. The edge transfer is described by the heredity coefficient $K$, reflecting a quantitative change in the property and equal to the ratio of the previous $S_{j}$ and subsequent $S_{j+1}$ property values [4]:

$$
K=S_{j} / S_{j+1} .
$$

In addition to the direct transfer of properties (Fig. 6) with technological and operational heredity, it is advisable to evaluate their interaction (Fig. 7).

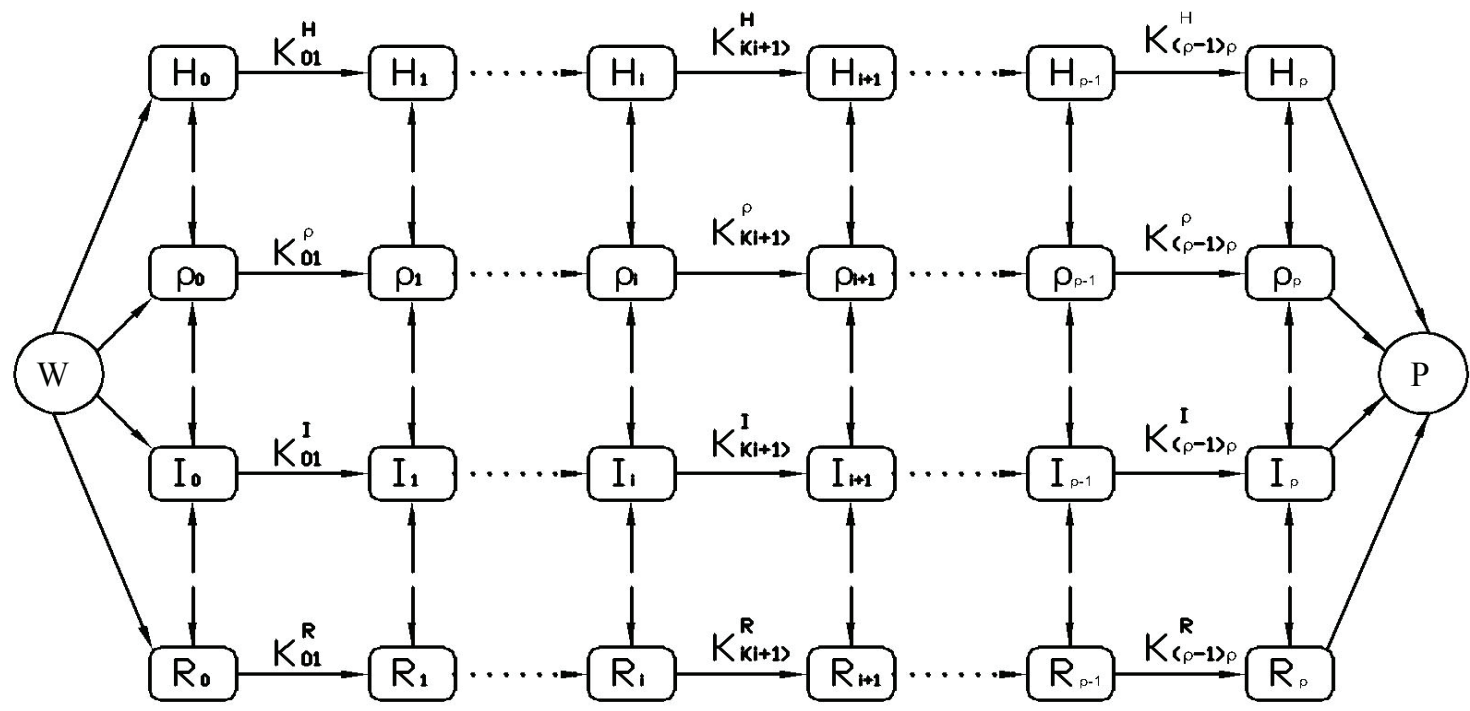

Fig. 6. A detailed graph of technological and operational heredity with a set of quality indicators

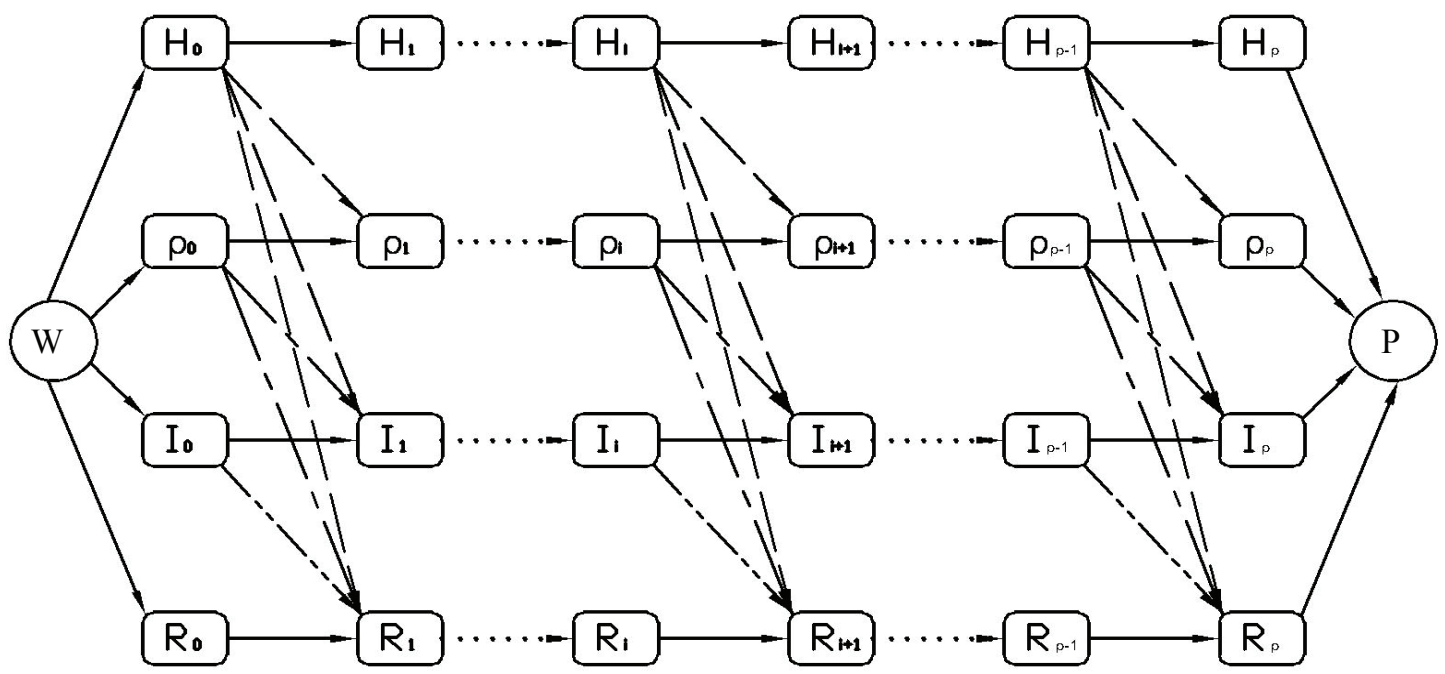

Fig. 7. The graph of technological and operational heredity reflecting the mutual influence of physico-mechanical and geometric quality indicators 
The general structure of the processes can be represented as a complex multidimensional system in the form of a sequence of changes in the basic parameters of the part quality [2]. The input of the technological processing system receive various characteristics of the workpiece $\left\{S_{10}, S_{20}, \ldots, S_{m 0}\right\}$, and the output provides the corresponding set of the same characteristics for the finished part $\left\{S_{1 p}, S_{2 p}, \ldots, S_{m p}\right\}$. These changes are determined by the combination of technological factors $\left\{t_{l 1}, t_{l 2}, \ldots, t_{l n}\right\}$ for each operation $\varphi_{l}$ of the technological process [3].

So for the quality parameter $S$ after final processing [2]:

$$
S_{p}=a_{p} S_{p-1}^{b_{p}}
$$

The quantitative connections of heritance, depending on the choice of the processing method, are determined by the coefficients $b$, and the basic conditions of processing inside this method are determined by the coefficients $a$. Performing transformations with equations for the preceding operations $\varphi_{p-1}, \varphi_{p-2}, \ldots, \varphi_{1}$, we obtained a general mathematical model for changing the quality parameter for the whole process:

$$
S_{p}=a_{p} a_{p-1}^{b_{p}} a_{p 2}^{\left(b_{p} b_{p-1}\right)} \ldots a_{1}^{\left(b_{p} b_{p-1} \ldots b_{2}\right)} S_{0}^{\left(b_{p} b_{p-1} \ldots b_{1}\right)} .
$$

The heredity coefficient $a_{l}$ describes the influence of technological factors $t_{l 1}, t_{l 2}, \ldots, t_{l n}$ on the considered quality parameter $S_{j}$ for operation $\varphi_{l}$ and can be represented as follows [3]:

$$
a_{1}=k_{l 0} t_{l 1}^{k_{l 1}} t_{l 2}^{k_{l 2} \ldots} t_{l n}^{k_{l n}}
$$

where $k_{l 0}, k_{l 1}, k_{l 2}, . ., k_{l n}$ are empirical coefficients of the influence of technological factors.

The analysis of dependences shows that the whole process can be expressed as the sum of the final operation and a certain fraction of the influence of the previous operations on the initial state of the workpiece $S_{0}$, which are determined by the heredity coefficients $b_{1}, b_{2}, \ldots, b_{p}$. If in any operation $\varphi_{l}$ the coefficient of technological heredity is $b_{l}=0$, the initial quality of the workpiece does not affect the final state after this operation, which can serve as an interpretation of $\varphi_{l}$ operation as an insurmountable "technological barrier" $[2,4]$.

\section{Main inherited quality indicators}

To identify the main quality indicators inherited in operation, through the control of which it is advisable to manage the technological process, the
$\mathrm{ABC}$ analysis was performed (Fig. 8), highlighting the reasons for the change in the initial geometric parameters of the surface and the physico-mechanical characteristics of the material during operation [5] .

The ABC analysis showed that in most cases, already during the running-in period (I), the roughness (1) and the surface relief structure (2) change significantly. The waviness (3) and the structure of the surface layers (4) change with steady wear (II). The accuracy of dimensions (5) and the geometric shape of the surface (6) remain within acceptable limits even at the beginning of the catastrophic wear stage (III). Only residual stresses (7) and the structure of the main material (8) can be maintained until the rubbing surfaces are completely destroyed [6].

Therefore, to study the heredity, we selected the operatively and least laboriously controlled physicomechanical geometric quality indicators from the initial and final groups $(0-C)$. At the same time, special attention was paid to indicators $(5,6)$ undergoing significant changes at the beginning of catastrophic wear (B) and related both to the physicomechanical characteristics of the material $(7,8)$ and to the geometric parameters of the surface relief $(1,3)$.

The study and management of the technological and operational heredity by the proposed method of quality parameters control was carried out for the parts responsible for the product life $[11,13]$.

Measurements of hardness HRC, shape deviations $\rho$, dimensional accuracy $I T$ and surface relief $R a$ were carried out on a batch of parts. It was divided into ten groups, and the arithmetic average of the group was taken as the calculated value.

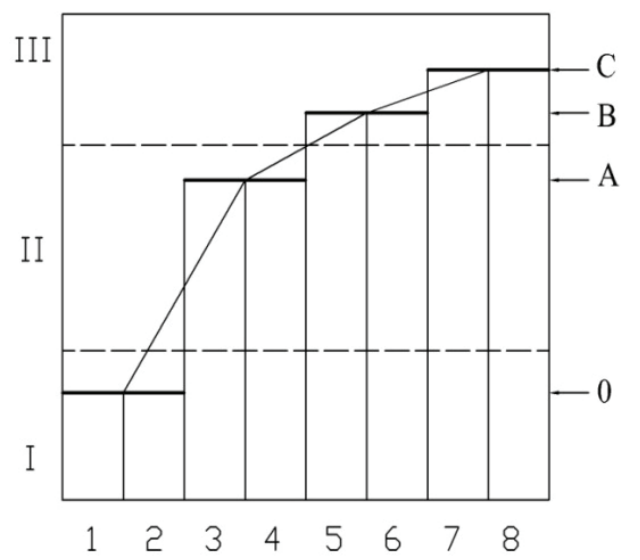

Fig. 8. ABC analysis of changes in operation process (I - III) of initial quality indicators $(1-8)$ :

0 - the surface formation; A - the change in contact loads; $\mathrm{B}$ - part failure; $\mathrm{C}$ - complete destruction of the surface; I - running-in; II - normal wear; III - catastrophic wear; 1 - the surface roughness; 2 - the surface relief structure; 3 - the surface waviness; 4 - the structure of the surface layers; 5 - the surface shape; 6 - the dimensional accuracy; 7 - residual stresses; 8 - the structure of the main material 
On the basis of the calculated results, the heredity transfer coefficients $K^{H}, K^{\rho}, K^{I}, K^{R}$ were determined for the graph in Fig. 6 and the coefficients of the technological effect heredity $K^{H \rho}, K^{H I}, K^{H R}, K^{\rho I}, K^{\rho R}$, $K^{I R}$ were done for the graph in Fig. 7.

To assess the heredity of the technological route, the resulting coefficients $K_{p}$ were calculated, equal to the product of the corresponding coefficients for the operational quality parameters throughout the entire sequence of operations. To determine the degree of heredity influence on various technological operations, the comparison coefficients $K_{c}$, equal to the ratio of mutual influence coefficients on the previous and subsequent operations, were calculated $[14,15]$.

\section{Technological barriers to properties transfer}

The study of the sequence of effects by concentrated energy flows on operations of combined processing and the analysis of the generated parameters of the surface quality are accompanied by the study of the technological heredity of dissipative structures formed in the processes of intensive processing $[16,17]$.

The formation of structures in the processes of physico-chemical processing is investigated from the standpoint of technological heredity, the sustainability of the quality parameters and processing performance.

Impacts of energy and substance flows impart impulses to the treated surface, and the speed and acceleration of their propagation are recorded at all parts of the way of impulses. So, the speed of energy propagation can be judged by the distribution of hardening parameters (Fig. 9, curves 1), and the substances by the concentration of alloying elements (Fig. 10) - by the depth of the surface layer. The magnitude of the pulse energy is proportional to the area located under the hardening curve, which can be determined by graphical integration (Fig. 9, curves 2). Acceleration, that is, the first derivative of the speed obtained by graphical differentiation (Fig. 9, curves 3), characterizes the magnitude and position of the resistance force to the penetration of the energy impulse into the surface layer.

Therefore, the second derivative of the energy impulse over the depth of the surface layer $\partial^{2}(\mathrm{P} \tau) / \partial \mathrm{H}^{2}$ can be considered as a technological barrier [17, 18]. The study of technological barriers shows that they are fairly accurately described by the normal distribution law with different values of dispersions.
The boundary conditions in the layer-by-layer formation of structures are recommended to determine by the size and position of the barriers describing the conditional interface of the layers [19, 20]. During hardening and softening, the barriers are located on opposite sides of the coordinate axis (Fig. 9b). With sufficient proximity of technological barriers, the combined action of mechanical and heat flows leads to the combination of barriers and thermal deformation strengthening along the entire depth of the combined effects (Fig. 9c). As a result of heating, the plasticity of the surface layer increases and deformations penetrate to a greater depth. The increase in the zone and degree of deformation, accompanied by increased heat absorption, prevents the passage and brings the boundary of the heat flow propagation to the surface. The combined action of mechanical and heat flows leads to the combination of technological barriers and thermo-mechanical processes occur throughout the entire depth of the impact.

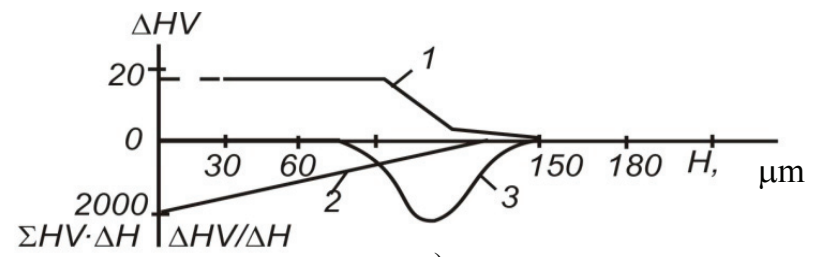

a)
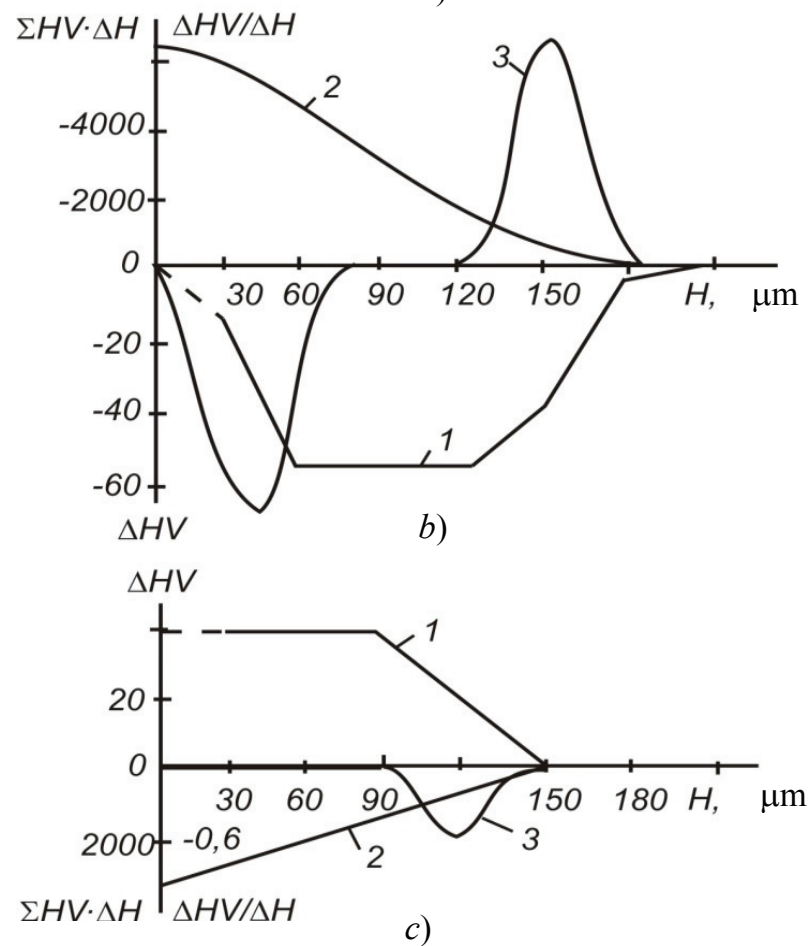

Fig. 9. Dependences of distribution over depth $H$ of surface layer:

1 - changes in hardness $\Delta H V ; 2$ - total hardening $\Sigma H V \Delta H$; 3 - hardening increment rates $\Delta H V / \Delta H$; after cutting with insufficient heating $(a)$, excess $(b)$ and rational $(c)$ intensity 


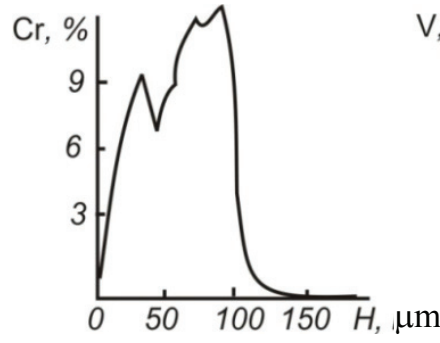

a)

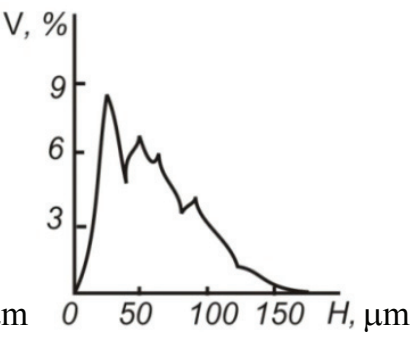

b)
Fig. 10. Dependences of distribution of $\mathrm{Cr}(a)$ and $\mathrm{V}(b)$ over depth $H$ of surface layer when surfacing with powder $\mathrm{C}-300(a)$ and when surfacing with $\mathrm{Fe}-\mathrm{V}$ powder with surface plastic deformation $(b)$

\section{Conclusion}

The technological heredity of operational properties in the processes of manufacturing machine parts is advisable to describe by the graph reflecting the coefficients of transmission and mutual influence of physico-mechanical and geometric parameters. To calculate the heredity coefficients according to the degree of the influence significance, a sequence of parameters is recommended: hardness $(H)$, shape deviation $(\rho)$, dimensional accuracy $(I)$, and surface relief roughness $(R)$ of the part surface.

Methods of technological management and control of the heredity of operational properties of parts include: measurements of physical, mechanical and geometric parameters of the most critical parts; determination of technological heredity mechanisms on the basis of transfer coefficient and coefficient of mutual influence of operational properties; analysis of technological barriers during intensive effects of energy flows; development of measures for technological management of technological processes.

\section{References}

1. Yashcheritsyn P.I., Kheifetz M.L., Chemisov B.P. Tekhnologicheskie Osnovy Vysokoeffektivnykh Metodov Obrabotki Detalej [Technological basis of highly efficient methods of parts processing]. Novopolotsk: Polotsk State University, 1996, 136 p.

2. Vasil'ev A.S., Dal'skij A.M., Klimenko S.A. Tekhnologicheskie Osnovy Upravleniya Kachestvom Mashin [Technological bases of quality management for machines]. Moscow: Mashinostroenie, 2003, 256 p. (Rus)

3. Yashcheritsyn P.I., Ryzhov E.V., Averchenkov V.I. Tekhnologicheskaya Nasledstvennost' V Mashinostroenii [Technological heredity in mechanical engineering]. Minsk: Nauka i teakhnika, 1977, $256 \mathrm{p}$.
4. Dal'skij A.M. Tekhnologicheskoe Obespechenie Nadezhnosti Vysokotochnykh Detalej Mashin [Technological support for the reliability of highprecision machine parts]. Moscow: Mashinostroenie, 1975, 223 p. (Rus)

5. Yashcheritsyn P.I., Skorynin Yu.V. Rabotosposobnost' Uzlov Treniya Mashin [Efficiency of friction units of machines]. Minsk: Nauka i teakhnika, 1984, $288 \mathrm{p}$.

6. Al'gin V.B., Blyumenshtejn V.YU., Vasil'ev A.S. Tekhnologicheskie i Ekspluatatsionnye Metody Obespecheniya Kachestva Mashin [Technological and operational methods to ensure the quality of machines]. Minsk: Belaruskaya navuka, 2010, 109 p.

7. Gordienko A.I., Kozhuro L.M., Kheifetz M.L., Kuhta S.V. Ispol'zovanie Kriteriev Podobiya dlya Kombinirovannykh Fiziko-khimicheskikh Metodov Obrabotki Materialov [The use of similarity criteria for combined physico-chemical methods of processing materials]. Doklady NAN Belarusi, 2004, vol. 48, issue 4, pp. 107-110.

8. Kheifetz M.L. Self-Organization of Structure Formation Processes in Intense Treatment and Operation of Materials. Advanced Materials and Technologies, 2016, issue 3, pp. 14-20.

9. Kolesnikov K.S., Balandin G.F., Dal'skij A.M. Tekhnologicheskie Osnovy Obespecheniya Kachestva Mashin [Technological basis for ensuring the quality of machines]. Moscow: Mashinostroenie, 1990, 256 p. (Rus)

10. Dal'skij A.M., Bazrov B.M., Vasil'ev A.S. Tekhnologicheskaya Nasledstvennost' v Mashinostroitel'nom Proizvodstve [Technological heredity in engineering production]. Moscow: Moscow Aviation Institute, 2000, 364 p. (Rus)

11. Yashcheritsyn P.I., Averchenkov V.I., Kheifetz M.L., Kuhta S.V. Analiz Svojstv Otnoshenij Tekhnologicheskikh Reshenij pri Proektirovanii Kombinirovannykh Metodov Obrabotki Materialov [The analysis of the properties of technological solutions in the design of combined materials processing methods]. Doklady NAN Belarusi, 2001, vol. 45, issue 4, pp. 106-109.

12. Yashcheritsyn P.I., Kheifetz M.L., Klimenko S.A., Vasil'ev A.S. Tekhnologicheskoe i Ekspluatatsionnoe Nasledovanie Pokazatelej Kachestva v Zhiznennom Tsikle Izdelij Mashinostroeniya [Technological and operational heredity of quality indicators in the life cycle of engineering products]. Doklady NAN Belarusi, 2005, vol. 49, issue 2, pp. 111-116.

13. Yashcheritsyn P.I., Kheifetz M.L., Tochilo V.S., Kusakin N.A. Upravlenie Spetsial'nymi Protsessami 
Sovmeshchennoj i Kombinirovannoj Obrabotki Detalej Mashin [The control of special processes of integrated and combined processing of machine parts]. Doklady NAN Belarusi, 2004, vol. 48, issue 6, pp. 113-118.

14. Yashcheritsyn P.I., Kusakin N.A., Kheifetz M.L., Prement G.B. Tekhnologicheskoe i Ekspluatatsionnoe Nasledovanie Pokazatelej Kachestva pri Vosstanovlenii Iznoshennyh Poverhnostej Detalej [Technological and operational heredity of quality indicators in the restoration of worn surfaces of parts]. Doklady NAN Belarusi, 2007, vol. 51, issue 6, pp. 121-126.

15. Kheifetz M.L., Lysov A.A. Kusakin N.A., Prement G.B. Upravlenie Nasledovaniem Pokazatelej Kachestva pri Vosstanovlenii, Obrabotke, Sborke i Ekspluatatsii Detalej Mashin [Controlling the heredity of quality indicators in the restoration, processing, assembly and operation of machine parts]. Sborka $v$ mashinostroenii, priborostroenii, 2009, issue 4 (105), pp. 30-35. (Rus)

16. Kheifetz M.L., Kozhuro L.M., Mrochek Zh.A. Protsessy Samoorganizatsii pri Formirovanii
Poverhnostej [Self-organization processes when forming surfaces]. Gomel': IMMS NAN Belarusi, 1999, $276 \mathrm{p}$.

17. Kheifetz M.L. Proektirovanie Processov Kombinirovannoj Obrabotki [The design of combined machining processes]. Moscow: Mashinostroenie, 2005, 272 p. (Rus)

18. Yashcheritsyn P.I., Kheifetz M.L., Shipko A.A., Kozhuro L.M. Tekhnologichesko-ekspluatatsionnye bar'ery v Poverhnostnom Sloe pri Vysokointensivnoj Obrabotke Materiala [Technological and operational barriers in the surface layer during high-intensity material processing]. Doklady NAN Belarusi, 1997, vol. 41, issue 5, pp. 110-113.

19. Kheifetz M.L. Formirovanie Svojstv Materialov pri Poslojnom Sinteze Detalej [The formation of the material properties in the layered synthesis of parts]. Novopolotsk: Polotsk State University, 2001, $156 \mathrm{p}$.

20. Kheifetz M.L. From Information and Additive Technologies to Self-Reproduction of Machines and Organisms. Advanced Materials and Technologies, 2018, issue 1, pp. 22-35. 